\title{
Pengelolaan Sampah Sekolah Pada Kelompok Pelestari Lingkungan Hidup SMKN 2 Denpasar
}

\author{
${ }^{1 *}$ I G K G Puritan W A, ${ }^{2}$ Ni Putu Desy Damayanthi, ${ }^{3}$ Shania Agatha Elleanor \\ Institut Teknologi dan Bisnis STIKOM Bali ${ }^{123}$ \\ puri@stikom-bali.ac.id, desy.damayanthi91@gmail.com, shaniaagatha84@gmail.com
}

\begin{abstract}
ABSTRAK
Mitra pada kegiatan pengabdian masyarakat ini adalah Kelompok Pelestari Lingkungan Hidup (PLH) SMKN 2 Denpasar. Kelompok ini adalah sebuah kelompok pencinta dan pelestari lingkungan hidup yang salah satu programnya adalah dalam menjaga kebersihan dan perhatiannya terhadap dampak sampah. Berdasarkan hasil diskusi dengan mitra maka didapat permasalahan bahwa masalah pengelolaan sampah yang belum terlalu baik pengelolaannya, terutama memilah mana sampah organik dan anorganik termasuk juga sampah yang dapat bernilai ekonomis jika ditangani dengan tepat. Upaya pemecahan masalah dalam pemahaman pemisahan sampah organik dan anorganik yang dapat ditingkatkan dengan pelatihan dan workshop pengolahan sampah, mengenalkan dan menerapkan Bank sampah berbasis sistem informasi pada guru/siswa dan PLH SMKN 2 Denpasar. Luaran yang telah dihasilkan melalui program pengabdian masyarakat ini adalah peserta dapat memilah sampah organik dan anorganik serta dapat mengetahui pemanfaatan sampah sehingga memiliki nilai yang ekonomis.
\end{abstract}

Kata kunci : lingkungan, organik anorganik, bank sampah

\section{ABSTRACT}

The partners ofthis community service activity are the Environmental Preservation Group (PLH) of SMKN 2 Denpasar. This group is a group of environmentalists and conservationists whose program is to maintain cleanliness and attention to the effects of waste. Based on the results of discussions with partners, it is found that the problem of waste management is not yet very well managed, especially where organic and inorganic waste is sorted, including waste that can be of economic value if handled properly. Efforts to solve problems in understanding the separation of organic and inorganic waste that can be improved by training and waste processing workshops, introducing and implementing information-based waste banks in teachers and PLH SMKN 2 Denpasar. The output that has been produced through this community service program is that participants can sort organic and inorganic waste and can know the use of waste so that it has economic value.

Keywords: environment, inorganic organic, waste bank 


\section{PENDAHULUAN}

Sampah merupakan bagian yang tidak dapat terpisahkan dari kehidupan manusia, karena pada dasarnya semua manusia pasti menghasilkan sampah. Sebelum terjadinya pencemaran lingkungan yang semakin meluas, pemanfaatan sampah harus diprioritaskan apalagi kalau sampai mengganggu kesehatan masyarakat. Pengelolaan sampah menjadi hal yang prioritas, pengelolaan sampah wajib dilaksanakan secara sistematis, menyeluruh, dan berkesinambungan yang meliputi pengurangan dan penanganan sampah.

Pengelolaan sampah disebutkan bahwa pengelolaan sampah bertujuan agar menjadikan sampah sebagai sumber daya seperti tertuang dalam Undang-Undang RI Tahun 2008 Nomor 18. Tak hanya itu UU 32 Th 2009 tentang Perlindungan dan Pengelolaan Lingkungan Hidup, Perda No 1 Th 2017 tentang PPLH, Perda No. 16 tahun 2009 tentang RUTRW Provinsi Bali, Perda no 8 th 2011 tentang pengelolaan sampah, dan yang terbaru Pergub 16 tahun 2016 tentang Baku Mutu Lingkungan Hidup dan Kriteria Baku Kerusakan Lingkungan Hidup mengisyaratkan bahwa pelestarian lingkungan hidup memerlukan pengelolaan yang baik.

Ditunjang juga dengan Peraturan Gubernur (Pergub) Bali No.97/2018 tentang Pembatasan Timbunan Sampah Plastik Sekali Pakai (PSP). Untuk itu SMKN 2 Denpasar memiliki sebuah kelompok Pelestari Lingkungan Hidup (PLH) yang beranggotakan siswa-siswa pencinta lingkungan hidup yang bersekolah pada SMKN 2 Denpasar sebagai salah satu perpanjangan sekolah dalam menciptakan lingkungan yang bersih dan lestari pada sekolah. Kelompok pelestari Lingkungan Hidup (PLH) SMKN
2 Denpasar adalah sebuah kelompok pecinta dan pelestari lingkungan hidup yang salah satu programnya adalah dalam menjaga kebersihan dan perhatiannya terhadap dampak sampah. Kelompok Pelestari Lingkungan Hidup beranggotakan 50 orang siswa 1 orang ketua dan wakil ketua serta seorang guru sebagai pembina Kelompok Pelestari lingkungan Hidup SMKN 2 Denpasar.

Cara pihak sekolah dalam menjaga lingkungan yaitu dengan menanamkan kesadaran pengelolaan sejak usia sekolah, maka siswa yang mampu memiliki kepedulian akan berusaha menjaga kehidupan berkelanjutan (Nurlaili, 2018). Hasil penelitian menunjukkan bahwa pembelajaran dengan menggunakan media daur ulang sampah mengakibatkan siswa lebih peduli terhadap lingkungan sekitarnya dan lebih mudah memahami proses pembelajaran di kelas. Namun pada kenyataannya, masyarakat di sekitar sekolah masih banyak yang kurang peduli terhadap sampah. Pembuangan sampah sebagian besar tidak diurus dengan baik dan hanya langsung dibuang tanpa proses pemilahan. Pada SMKN 2 Denpasar masih terdapat sampah-sampah yang belum terpilah ataupun bisa dikatakan belum terkelola dengan baik (Suryati, 2009), (Ulfah, Normelani and Arisanty, 2016).

Dalam hal meningkatkan pengelolaan sampah pada sekolah saat ini sosisalisasi pengelolaan sampah pihak sekolah hanya menerapkan menggunakan himbauan verbal pada saat pembelajaran maupun pengumuman-pengumuman tertulis pada sekitar area sekolah jika dihubungkan dengan minat anak-anak usia sekolah menengah atas di tahun ini sangat sering mengakses media sosial daring dalam kesehariannya sehingga bisa menyebabkan pengaruhnya pada kepekaan isu-isu sosial 
di sekitar siswa tersebut (E.B. and S.W., 2017), dirasa menjadi hal yang kurang mengena dalam keberlangsungan rekayasa sosial kesadaran akan sampah. Di sini terlihat bahwa media komunikasi yang dilakukan pihak sekolah dan yang digunakan siswa menjadi kurang pas padanannya.

Kelompok Pelestari Lingkungan Hidup pada SMKN 2 Denpasar mempunyai peran penting karena seharusnya anggota-anggota Pelestari Lingkungan Hidup (PLH) SMKN 2 Denpasar yang juga adalah siswa mampu membantu pihak sekolah dalam menyebarkan himbauan dan informasi tentang pengelolaan sampah melalui akunakun media sosial mereka. Di sinilah peranan penting kelompok Pelestari lingkungan hidup SMKN 2 Denpasar untuk dapat berkontribusi dalam menjaga lingkungan bersih dan lestari. Namun karena anggota dari Pelestari Lingkungan Hidup (PLH) SMKN 2 Denpasar masih berusia remaja, menurut pembina sekolah tersebut para anggota PLH SMKN 2 Denpasar berpotensi menyebarkan himbauan pengelolaan sampah menggunakan akun-akun media sosial mereka. Efektifitas pengaruh sosial pada anak sekolah cukup berpengaruh pada interaksi di media sosial (Andarsih and Mayangsari, 2018).

Untuk memanfaatkan dan meningkatkan pengelolaan sampah, digunakanlah program bank sampah. Bank sampah merupakan suatu tempat yang digunakan untuk mengumpulkan sampah. Sampah yang sudah dipilah-pilah dan hasil dari pengumpulan sampah yang sudah dipilah disetorkan ke tempat pembuatan kerajinan dari sampah atau ke tempat pengepul sampah. Bank sampah ini dikelola menggunakan sistem seperti perbankkan yang dilakukan oleh petugas sukarelawan. Penyetor adalah warga yang tinggal di sekitar lokasi bank serta mendapat buku tabungan seperti menabung di bank.

Program bank sampah ini merupakan solusi yang ditawarkan agar dapat mengelola sampah dengan baik. Tujuan bank sampah selanjutnya adalah untuk menyadarkan masyarakat tentang lingkungan yang sehat, rapi, dan bersih. Program bank sampah digunakan untuk mengubah sampah menjadi sesuatu yang lebih berguna dalam masyarakat, misalnya untuk kerajinan dan pupuk yang memiliki nilai ekonomis.

Anggota PLH SMKN 2 Denpasar dapat memilah sampah sesuai dengan jenisnya dan dapat menyikapi masalah sampah dengan bijak dengan menerapkan program bank sampah. Di samping dapat menerapkan pemilahan sampah di sekolah, siswa juga dapat mengajak masyarakat di sekitar sekolah untuk mengikuti program bank sampah. Seperti yang disampaikan di atas, anggota PLH SMKN 2 Denpasar telah mengadakan sosialisasi untuk menghimbau cara pengelolaan sampah menggunakan akun di sosial media.

Sosialisasi menggunakan program bank sampah sebagai program utama untuk mengajak masyarakat dalam menngelola sampah. Masyarakat diajak untuk lebih bijaksana dalam mengelola sampah agar menjadi produk yang memiliki nilai. Siswa dan masyarakat akan bersinergi untuk menyikapi masalah sampah yang selalu menjadi bulan-bulanan dan belajar memilah sampah sesuai dengan jenisnya. Kegiataan ini telah dapat merangsang siswa dan masyarakat agar tidak menyepelekan sampah dan mengubah sudut pandang bahwa sampah 
bisa menjadi barang yang memiliki nilai ekonomis.

Tabel 1. Analisis Situasi

\begin{tabular}{|l|l|l|l|}
\hline No & Bidang & $\begin{array}{l}\text { Permasalah } \\
\text { an }\end{array}$ & Solusi \\
\hline 1 & $\begin{array}{l}\text { Pengelo } \\
\text { laan } \\
\text { Sampah }\end{array}$ & $\begin{array}{l}\text { Pemisahan } \\
\text { sampah } \\
\text { Organik dan } \\
\text { anorganik }\end{array}$ & $\begin{array}{l}\text { Pelatihan } \\
\text { dan } \\
\text { workshop } \\
\text { pengolaha } \\
\text { n sampah }\end{array}$ \\
\hline 2 & $\begin{array}{l}\text { Nilai } \\
\text { Ekono } \\
\text { mis } \\
\text { hasil } \\
\text { olahan } \\
\text { Sampah }\end{array}$ & $\begin{array}{l}\text { Pengelolaan } \\
\text { nilai } \\
\text { ekonomis } \\
\text { olahan } \\
\text { sampah }\end{array}$ & $\begin{array}{l}\text { Pelatihan } \\
\text { pengolaha } \\
\text { n sampah }\end{array}$ \\
\hline
\end{tabular}

\section{RUMUSAN MASALAH}

Bagaimana menangani secara tepat untuk meningkatkan pengelolaan sampah, terutama dalam hal memilah mana sampah organik dan anorganik, termasuk juga sampah yang dapat bernilai ekonomis?

\section{METODE}

Pengabdian Masyarakat pelatihan dan penyuluhan dilakukan di Jl. Pendidikan No.28, Sidakarya, Kec. Denpasar Selatan, Kota Denpasar, Bali 80224. Lokasi mitra berjarak hanya sekitar 11 menit dari ITB STIKOM Bali. Kegiatan pelatihan pelatihan dan workshop pengolahan sampah. Para anggota Kelompok PLH SMKN 2 Denpasar dilatih bagaimana mengelola sampah dan memilah sampah organik dan anorganik juga dilatih bagaimana memanfaatkan sampah organik menjadi kompos juga sampah plastik dan sebagainya agar bisa lebih bernilai dan ditabung. Pendampingan selama tiga bulan juga dilakukan setelah pelatihan untuk memastikan kelompok PLH SMKN 2 Denpasar berkesinambungan dalam memanfaatkan mengkampanyekan dan memberikan himbauan pentingnya mengelola dan pemilahan.

Pada Tabel 2 adalah susunan kegiatan pelatihan.

Tabel 2

\begin{tabular}{|c|l|c|}
\hline No & \multicolumn{1}{|c|}{ Acara Pelatihan 1 } & Durasi \\
\hline 1. & Perkenalan & 5 Menit \\
\hline 2. & Pelatihan Pengelolaan sampah & 10 Menit \\
\hline 3. & $\begin{array}{l}\text { Pendampingan Praktek } \\
\text { pemilahan dan pengelolaan } \\
\text { sampah }\end{array}$ & 90 Menit \\
\hline 4. & Penutup & 5 Menit \\
\hline
\end{tabular}

\section{PEMBAHASAN}

Tahap pertama dilaksanakan patihan Pengenalan dasar-dasar pengelolaan sampah. Sebelum memulai pelatihan, peserta pelatihan diberikan dasar-dasar pengelolaan sampah terlebih dahulu. Materi yang diberikan terdiri dari:

a. Pelatihan Tentang Jenis-Jenis Sampah.

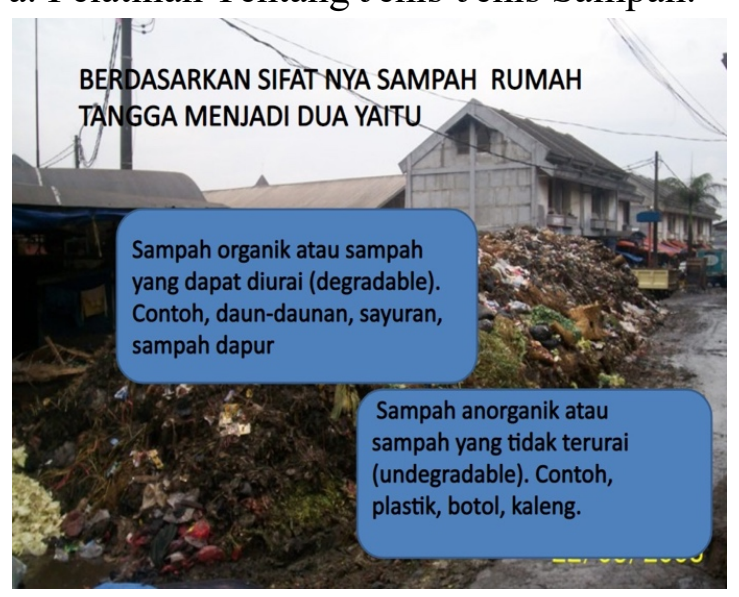

Gambar 1 Materi jenis-jenis sampah 
Para peserta diberikan tentang pengetahuan bagaimana sampah diolah sesuai dengan jenis-jenis sampah seperti yang paling utama dipisahkan adalah sampah organik dan sampah anorganik.

Sampah organik adalah sampah yang dapat terurai seperti dedaunan, sayuran, sampah dapur. Sedangkan sampah anorganik adalah sampah yang tidak terurai di alam yaitu (plastik, botol, kaleng, kaca, an lain-lain). Untuk karakteristik beberpa contoh jenis sampah dapat terlihat pada Gambar 2.

\begin{tabular}{|c|c|}
\hline Jenis Sampah & Waktu Terurai \\
\hline Kulit Jeruk dan Pisang & 2 tahul \\
\hline Puntung Rokok & 1-5 tahun \\
\hline Kain Nilon & $30-40$ tahun \\
\hline Jaring Ikan & $30-40$ tahun \\
\hline Kulit & 50 tahun \\
\hline Kaleng Aluminium & $80-100$ tahun \\
\hline Kantong Plastik & $20-1.000$ tahun \\
\hline Botol Plastik & Tidak dapat diperkirakan \\
\hline Baterai Bekas & 1.000 tahun \\
\hline Botol Kaca & 1.000 .000 tahun \\
\hline
\end{tabular}

Gambar 2 Karakteristik Jenis-jenis sampah

b. Pelatihan Pemilahan sampah sesuai jenisnya.

Peserta dilatih juga bagaimana memilah sampah sesuai jenisnya dan menyimpan hasil dari sampah-sampah yang telah dipilah. Hasil pemilahan disimpan atau disediakan tempat seperti pada Gambar 3, bisa berupa tong/tempat sampah sesuai dengan jenis yaitu organik atau anorganik.

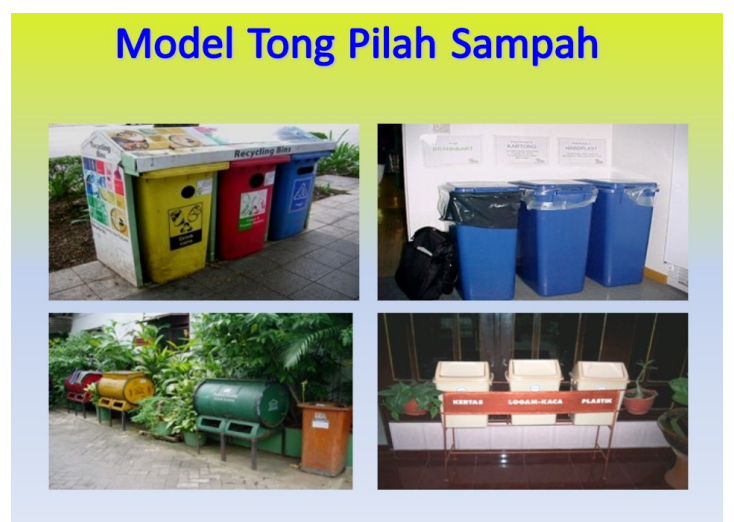

Gambar 3 Jenis tempat penyimpanan dan pemilahan sampah

c. Pemanfaatan sampah setelah dipilah.

Selanjutnya para peserta pelatihan diajarkan bagaimana memanfaatkan sampah-sampah hasil pemilahan. Para peserta diajarkan dari setiap jenis sampah bagaimana pengolahannya dan bagaimana tahapan setiap jenis sampah tersebut dipilah dan diproses. Peserta diajarkan setiap tahap-tahap tersebut seperti terlihat pada Gambar 4, yaitu bagaimana proses pemilahan sampah. 


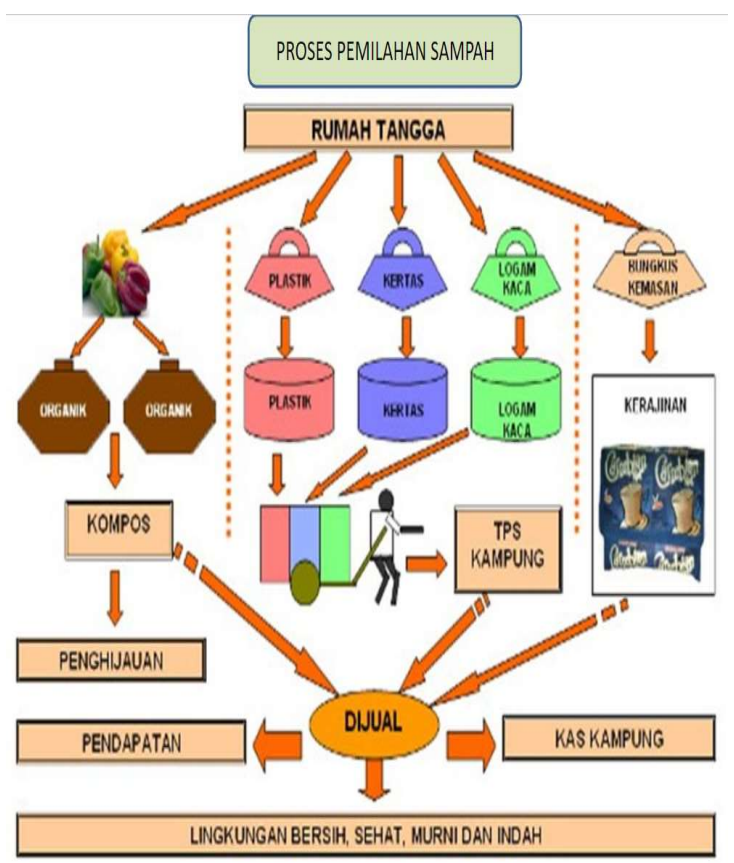

Gambar 4 Proses Pemilahan Sampah

d. Menjadikan hasil pemilahan dan pengolahan sampah menjadi bernilai ekonomis. Berbagai contoh diberikan tentang bagaimana setiap sampah hasil pemilahan dapat dijadikan barang-barang ataupun hasil karya yang bersifat ekonomis. Seperti tas, vas bunga, karya seni dan lain-lain dari sampah-sampah jenis anorganik, sedangkan sampahsampah organik dapat dijadikan kompos sehingga dapat dijual untuk memperoleh nilai ekonomis hasil pemilahan sampahsampah tersebut.

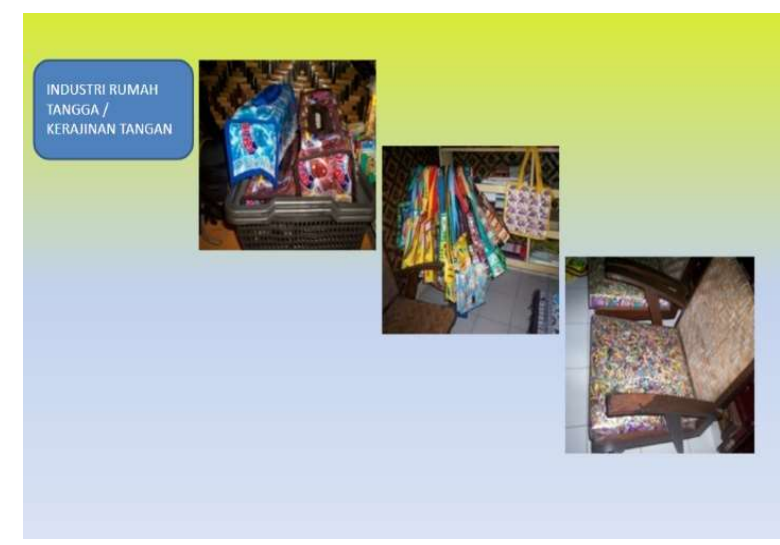

Gambar 5 Sampah menjadi bernilai ekonomis

Tahap kedua dari program Pengelolaan sampah yaitu pendampingan praktek pemilahan dan pengelolaan sampah. Dalam praktek ini, para peserta diminta menyiapkan kantung-kantung sampah untuk proses pengumpulan sampah di sekolah dan juga untuk memilah sampah yang telah dikumpulkan.

Pada saat melakukan praktik pemilahan dan pengelolaan sampah para peserta sudah menyiapkan kantungkantung sampah dan mengumpulkan sampah untuk pelatihan di masing-masing ruang kelas belajar. Ada beberapa jenis sampah yang paling banyak ditemukan di kelas-kelas dan di lingkungan sekolah, antara lain sampah jenis botol plastik dan kertas bekas. Sampah jenis anorganik lain yang terkumpul adalah plastik kresek ataupun plastik pembungkus makanan.

Jenis sampah organik seperti dedaunan dan sayuran sedikit sekali ditemukan di ruang-ruang kelas. Hanya ditemukan sisa-sisa makanan saja dan tidak terlalu banyak. Untuk itu pelatihan difokuskan pada hasil pemilahan sampah anorganik berupa botol-botol bekas minuman dan kertas bekas tak terpakai. Terlihat pada gambar 5 para peserta mengumpulkan dan memilah hasil pengumpulan sampah serta proses 
memisahkan tutup botol-botol plastik dan label kemasan botol-botol plastik tersebut.
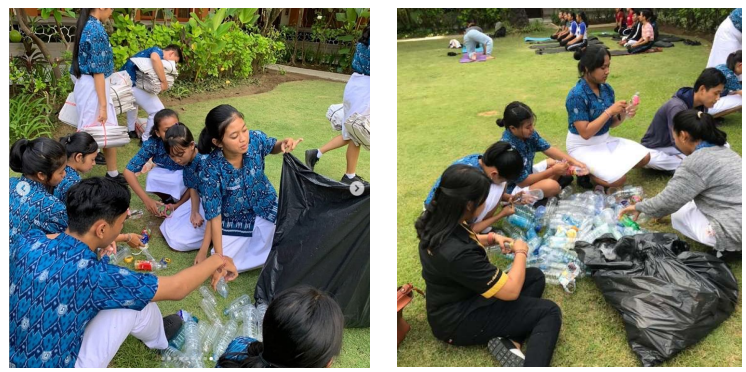

Gambar 5 Pengumpulan dan pemilahan sampah

Pada tahap ketiga dilakukan sesi tanya jawab dan diskusi tentang bagaimana proses pemilahan sampah bernilai ekonomis tersebut bisa dijadikan sebuah kegiatan yang dapat membantu kegiatan kelompok PLH SMKN 2 Denpasar. Selain itu, ada juga tanya jawab tentang bank sampah. Pada sesi ketiga ini juga dilakukan tanya jawab tentang bagaimana kebermanfaatan dari program pengelolaan sampah tersebut. Gambar 6 di bawah ini adalah dokumentasi pelaksanaan diskusi dan tanya jawab.

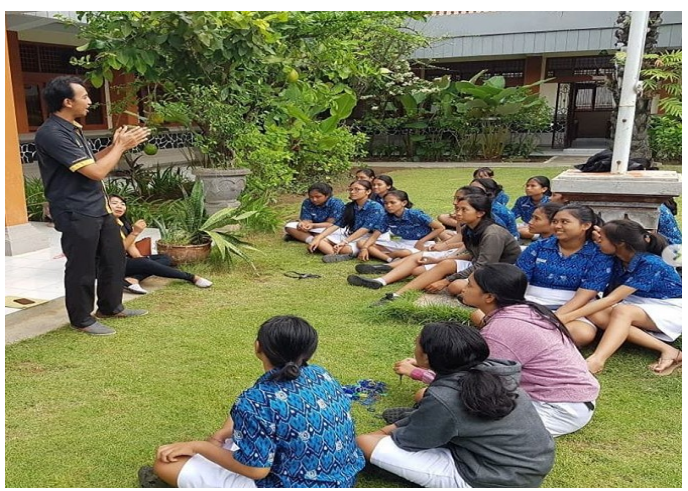

Gambar 6 Diskusi dan tanya jawab pengelolaan sampah

\section{SIMPULAN}

Antusias para siswa dalam pemilahan sampah cukup tinggi terutama pada saat pamahaman materi tentang pemanfaatan sampah yang ditemukan di ruang kelas dan lingkungan sekolah sehingga sampah tersebut menjadi bernilai ekonomis. Anggota PALH sudah 100\% dapat lebih mengenal bagaimana mengelola sampah di sekolah dan mengetahui nilai ekonomis dari hasil olahan sampah. Hasil lain yang dicapai adalah meningkatnya seluruh kemampuan para peserta dalam mengelola sampah lebih khususnya pada pemilahan sampah organik dan anorganik juga pemanfaatan hasil dari pemilahan menjadi bernilai ekonomis.

\section{UCAPAN TERIMA KASIH}

Kami mengucapkan terima kasih kepada PLH SMKN 2 Denpasar, Institut Teknologi dan Bisnis STIKOM Bali, para instruktur dan narasumber sehingga kegiatan pengabdian pengelolaan sampah ini bisa terlaksana dengan baik dan lancar.

\section{DAFTAR PUSTAKA}

Andarsih, Y. and Mayangsari, I. (2018) 'Strategi Komunikasi Program Bandung Cleanaction dalam Mengkampanyekan Gerakan Pungut Sampah (GPS)', dialektika, 5, no. Available at: http://journal.unla.ac.id/index.php/di alektika/issue/view/11.

E.B., G. A. and S.W., E. D. (2017) 'Hubungan Penggunaan Media Sosial dengan Tingkat Kepekaan Sosial di Usia Remaja', Jurnal The Messenger. Universitas Semarang, $9(1), \quad$ p. $65 . \quad$ doi: 10.26623/themessenger.v9i1.428.

Nurlaili, S. (2018) 'Pengenalan Ecoliteracy Melalui Media Pembelajaran Dari Sampah di Sekolah Dasar', Journal AL-MUDARRIS. STAI Mahad Aly Al-Hikam Malang, 1(2), p. $\quad 76$. doi: 10.32478/al- 
mudarris.v1i2.171.

Suryati, T. (2009) Bijak dan Cerdas Mengolah Sampah, PT. Agromedia Pustaka. Jakarta.

Ulfah, N. A., Normelani, E. and Arisanty, D. (2016) 'STUDI EFEKTIFITAS BANK SAMPAH SEBAGAI SALAH SATU PENDEKATAN DALAM PENGELOLAAN SAMPAH TINGKAT SEKOLAH MENENGAH ATAS (SMA) DI BANJARMASIN', JPG (Jurnal Pendidikan Geografi), 3(5). doi: 10.20527/JPG.V3I5.2298. 